\title{
Improvement of the Resistance of Lactobacillus delbrueckii ssp. bulgaricus to Freezing by Natural Selection
}

\author{
C. Monnet, C. Béal, and G. Corrieu \\ Unité Mixte de Recherche Génie et Microbiologie des Procédés Alimentaires, \\ Institut National de la Recherche Agronomique, \\ 78850 Thiverval-Grignon, France
}

\section{ABSTRACT}

Lactic acid bacteria are often produced as frozen or freeze-dried cultures that can be used for the direct inoculation of milk in cheese and fermented milk production processes. The objective of this study was to investigate whether the resistance of Lactobacillus delbrueckii ssp. bulgaricus to freezing could be improved by natural selection. Three parallel cultures of strain CFL1 were propagated for 30 cycles in which each cycle involved three serial transfers through milk, one freezing step, and one thawing step. The concentration in viable cells after thawing as well as the acidifying activity of the thawed cultures increased dramatically throughout the experiment. This may be explained by the random appearance of better-adapted mutants that can outcompete the other genotypes. However, after 30 cycles of subcultivation, freezing, and thawing, all the cultures contained subpopulations having different survival rates to freezing. Our results show that serial transfer culture experiments may be used to improve technological properties of lactic acid bacteria. Furthermore, investigation of the mutations that are responsible for an increased cryotolerance may help to define new targets for improving the resistance of lactic acid bacteria to several stresses.

(Key words: lactic acid bacteria, freezing, acidifying activity, Lactobacillus)

Abbreviation key: RAPD = randomly amplified polymorphic DNA.

\section{INTRODUCTION}

Lactic acid bacteria belonging to the genus Lactobacillus are used in the manufacture of several kinds of cheeses and fermented milks. Their main function is the production of lactic acid. However, they may also

Received February 26, 2003.

Accepted April 28, 2003.

Corresponding author: C. Monnet; e-mail: monnet@grignon. inra.fr. be chosen for their contribution to aroma and texture, as well as for their probiotic role. They are generally used in mixed cultures containing other lactic acid bacteria (Hassan and Frank, 2001). In industrial processes, these cultures are often added to the milk as concentrated starter cultures that are in a frozen or freezedried form. Compared to the traditional inoculation procedure, which consists of growing several successive cultures with a progressive increase in the culture volume, utilization of concentrated starter cultures has several advantages, such as increased flexibility in the fermentation process and standardization of biological activity (Lejard et al., 1994). However, lactic acid bacteria, and especially lactobacilli, often have a poor resistance to freezing or freeze-drying, which suggests why many strains cannot be easily produced in a frozen or freeze-dried form. Freezing has several deleterious effects on the cells. The formation of ice crystals induces mechanical damage on membranes and other cellular components (Mazur, 1965). Crystallization of water also leads to a cryoconcentration of the solutes, which induces some osmotic damage (Meryman, 1968). It has also been shown that an oxidative stress may occur during freeze-thaw treatments (Park et al., 1998; Stead and Park, 2000).

During the production of frozen concentrated starter cultures, several operating conditions have a great influence on the resistance of lactic acid bacteria to freezing (Fonseca et al., 2001), and numerous studies have been devoted to optimizing factors such as the composition of the culture medium or the addition of protective agents. Resistance to freezing may also be improved by applying moderate stress conditions before freezing (De Urraza and De Antoni, 1997; Kim and Dunn, 1997; Teixeira et al., 1997; Poirier et al., 1998; Broadbent and Lin, 1999; Béal et al., 2001). This is due to physiological changes such as synthesis of specific stress proteins (Whitaker and Batt, 1991; Panoff et al., 1994; Panoff et al., 1998; Broadbent and Lin, 1999) or modification of fatty acid composition of the membrane (Teixeira et al., 1996; Béal et al., 2001). Resistance of the bacterial cells to freezing may also be improved by genetic engineering. For example, overproduction of the cold shock 
proteins $\mathrm{CspB}$ and $\mathrm{CspE}$ increases the survival of Lactococcus lactis after four freeze-thaw cycles of a 10- and 5fold factor, respectively (Wouters et al., 2000). Another way to generate strains with improved cryotolerance would be to select better-adapted genetic variants by natural selection. This might be achieved by performing successive cycles of cultivation that include freezing and thawing of the culture. Theoretically, if betteradapted spontaneous mutants appear, they will progressively outcompete the initial genotype (Dykhuizen, 1990). However, to our knowledge, such an approach has not yet been investigated.

The objective of the present work was to increase the cryotolerance of lactobacilli by natural selection. Such an increase should improve the acidifying activity of frozen cultures of lactobacilli. In this work, we studied the evolution of strain $L$. delbrueckii ssp. bulgaricus CFL1 during 30 successive cycles in which each cycle involved three serial transfers through milk, one freezing step, and one thawing step. Like many lactobacilli (Tsvetkov and Shishkova, 1982), strain CFL1 has a low resistance to freezing. Three separate cultures were done in parallel to study the among-population diversity. The within-population diversity of the cultures was also investigated.

\section{MATERIALS AND METHODS}

\section{Bacterial Strain and Culture Conditions}

After purification on MRS agar (de Man et al., 1960), L. delbrueckii ssp. bulgaricus CFL1 (INRA, ThivervalGrignon, France) was cultivated for $24 \mathrm{~h}$ at $42^{\circ} \mathrm{C}$ in 5 $\mathrm{ml}$ of reconstituted skim milk (100 g/L; Elle et Vire, Condé-sur-Vire, France) that had been sterilized for 15 min at $110^{\circ} \mathrm{C}$. Thirty cycles, in which each cycle involved three serial transfers through milk, one freezing step, and one thawing step, were then performed. In each cycle, $250 \mathrm{ml}$ of reconstituted skim milk that had been sterilized for $15 \mathrm{~min}$ at $110^{\circ} \mathrm{C}$ was inoculated at $0.4 \%$ (vol/vol) and incubated for $24 \mathrm{~h}$ at $42^{\circ} \mathrm{C}$. After two other successive subcultures, $4 \mathrm{ml}$ of the culture was poured in a 8-ml volume glass tube, which was then placed in $50 \% \mathrm{CaCl}_{2}(\mathrm{wt} / \mathrm{vol})$ at $-16^{\circ} \mathrm{C}$ for $96 \mathrm{~h}$. The frozen sample was then thawed for $10 \mathrm{~min}$ in a water bath at $30^{\circ} \mathrm{C}$ and used for performing another subcultivation/freezing/thawing cycle. At each cycle, an aliquot of the culture was recovered before freezing at $-16^{\circ} \mathrm{C}$ to preserve the cells for a long period. This was done by adding $5 \mathrm{ml}$ of reconstituted skim milk and $0.75 \mathrm{ml}$ of glycerol to $1 \mathrm{ml}$ of culture, and the resulting mixture was stored at $-80^{\circ} \mathrm{C}$.

\section{Randomly Amplified Polymorphic DNA (RAPD) Analysis}

Each culture to be analyzed was inoculated in MRS broth and incubated for $24 \mathrm{~h}$ at $42^{\circ} \mathrm{C}$. This culture was then inoculated at $2 \%(\mathrm{vol} / \mathrm{vol})$ in another tube containing MRS broth, and the cells were recovered by centrifugation at the end of the exponential growth phase. Total DNA was extracted from bacterial cells (de los Reyes-Gavilan et al., 1992) and RAPD analysis was performed with the oligonucleotide 1254 (5'CCGCAGCCAA-3') as described by Akopyanz and coworkers (1992).

\section{Measurement of the Acidifying Activity}

Acidifying activity of the cultures was measured before freezing at $-16^{\circ} \mathrm{C}$ and after thawing. Two hundred fifty milliliters of reconstituted skim milk was inoculated at $0.4 \%$ and placed in a water bath at $42^{\circ} \mathrm{C}$. The $\mathrm{pH}$ was continuously measured during $15 \mathrm{~h}$ using a CINAC apparatus (Ysebaert, Frépillon, France), and the time necessary to reach $\mathrm{pH} 5.5\left(\mathrm{t}_{\mathrm{pH} 5.5}\right.$ in $\left.\mathrm{min}\right)$ was then determined (a low $t_{\mathrm{pH} 5.5}$ value corresponds to a high acidifying activity).

\section{Measurement of Viable Cell Concentration}

Viable cell concentration in the cultures was determined before freezing at $-16^{\circ} \mathrm{C}$ and after thawing. The samples were diluted $(1 / 100, \mathrm{vol} / \mathrm{vol})$ in tryptone-salt solution ( $1 \mathrm{~g}$ of tryptone and $8.5 \mathrm{~g}$ of $\mathrm{NaCl}$ per liter) and vortexed for $1 \mathrm{~min}$. After further dilution in tryptone-salt solution, $1 \mathrm{ml}$ of the bacterial suspension was mixed with molten MRS agar, and the colonies were enumerated after incubating the agar plates in anaerobiosis (Genboxanaer, Biomérieux, Marcy l'Etoile, France) for $2 \mathrm{~d}$ at $42^{\circ} \mathrm{C}$.

\section{RESULTS}

\section{Evolution of the Viability and the Acidifying Activity of Lactobacillus delbrueckii ssp. bulgaricus CFL1 During 30 Cycles of Subcultivation, Freezing, and Thawing}

A single colony of strain CFL1 was inoculated in three separate cultures, named A, B, and C, which were then used for 30 successive cycles of subcultivation, freezing, and thawing, as described in materials and methods. Evolution of the viable cell concentration in these cultures, before freezing and after thawing, as well as their acidifying activity, is shown in Figure 1. No significant increase of the viable cell concentration before freezing could be observed in culture A (Figure 1A). However, 


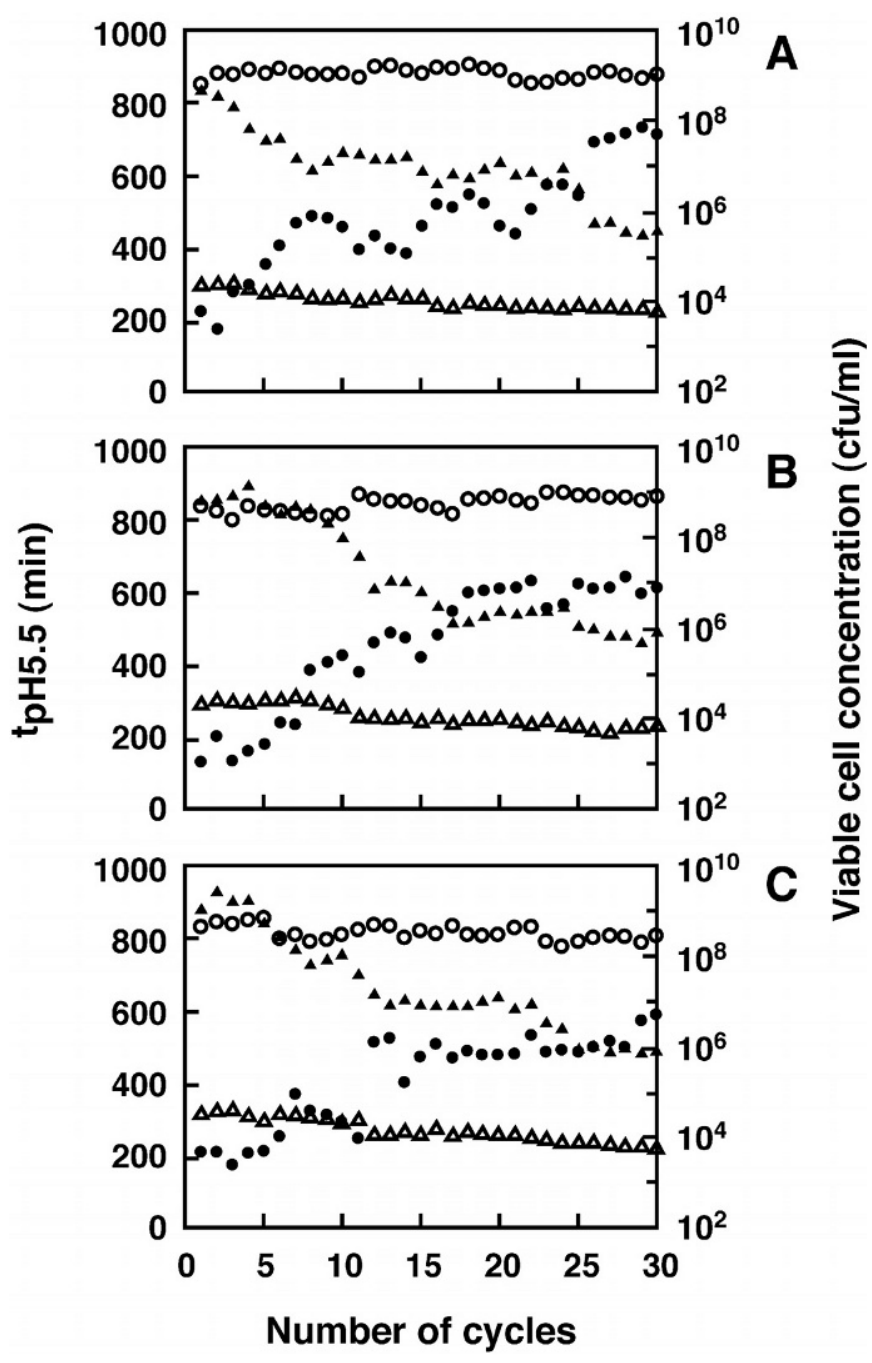

Figure 1. Evolution of the viable cell concentration $(\bigcirc, \mathbf{0})$ and of the time necessary to reach $\mathrm{pH} 5.5(\triangle, \boldsymbol{\Delta})$ before freezing (open symbols) and after thawing (closed symbols) during 30 cycles of subcultivation, freezing, and thawing of cultures A (A), B (B), and C (C).

the acidifying activity before freezing increased slightly. Indeed, the time necessary to reach $\mathrm{pH} 5.5$ $\left(t_{\mathrm{pH} 5.5}\right)$ decreased from $288 \mathrm{~min}$ at the beginning of the experiment, to $221 \mathrm{~min}$ after 30 cycles. The viable cell concentration in culture A after thawing increased dramatically throughout the experiment. After the first thawing, only $5.9 \times 10^{3} \mathrm{cfu} / \mathrm{ml}$ were enumerated, which corresponded to a survival rate of $10^{-5}$. After the 30th thawing, the viable cell concentration was $4.8 \times 10^{7} \mathrm{cfu} /$ $\mathrm{ml}$, which corresponded to a survival rate of $4.3 \times 10^{-2}$. This increase was not linear and, at several stages, there was stagnation or a temporary decrease in the viable cell concentration after thawing. There was also a strong increase in the acidifying activity of culture A after thawing, as the $t_{\mathrm{pH} 5.5}$ value decreased from 830 min at the beginning of the experiment, to $439 \mathrm{~min}$ after 30 cycles. As in culture A, culture B showed a slight decrease in the $t_{p H 5.5}$ value before freezing, a dramatic decrease in the $t_{\mathrm{pH} 5.5}$ value after thawing, and a dramatic increase in the viable cell concentration after thawing (Figure 1B). However, the corresponding curves differed significantly from those of culture A. For example, in culture $A$ the $t_{\mathrm{pH} 5.5}$ value after thawing started to decrease at the beginning of the experiment, whereas in culture B, it began to decrease only after the 8th cycle. The overall evolution of the $t_{\mathrm{pH} 5.5}$ value before freezing and after thawing, as well as of the viable cell concentration after freezing in culture $\mathrm{C}$ was similar to that in the two other cultures.

In the three cultures, there was a good relationship between the logarithm of population after thawing and the time necessary to reach $\mathrm{pH} 5.5$ (data not shown). Linear regression of the data for culture A resulted in the following equation:

$$
\mathrm{t}_{\mathrm{pH} 5.5}=-86 \times \log (\text { population })+1114\left(\mathrm{r}^{2}=0.94\right) \text {. }
$$

For cultures $\mathrm{B}$ and $\mathrm{C}$, the slope of the equation was -102 and -122 , respectively ( $\mathrm{r}^{2}$ value was 0.90 and 0.85 , respectively). This means that differences in the acidifying activity of the thawed cultures may be the result of differences in the concentration of viable cells after thawing.

Even if the three cultures more rapidly reached a low $\mathrm{pH}$ after 30 cycles of subcultivation, freezing, and thawing, there was no significant evolution of the $\mathrm{pH}$ after $24 \mathrm{~h}$ of growth, which was always near 3.7 to 3.9 (results not shown). At this $\mathrm{pH}$, strains of $L$. delbrueckii ssp. bulgaricus are not able to grow, which indicates that cells were always in the stationary growth phase when freezing treatment was applied.

\section{RAPD Analysis}

To verify the absence of contamination, RAPD analysis was performed after the 30th cycle of subcultivation, freezing, and thawing of the parallel cultures A, B, and C. The percentage of similarity between the corresponding RAPD profiles and the profile of the initial culture was $96.3,97.9$, and $96.0 \%$, respectively. The percentages of similarity that were obtained when the RAPD profile of the initial culture was compared with those of two other repetitions of the initial culture were 94.7 and $99.0 \%$. It can thus be concluded that the RAPD profile did not evolve significantly during the 30 cycles of subcultivation, freezing, and thawing. As the oligonucleotide that was used in the RAPD analysis provides highly polymorphic profiles (Torriani et al., 1999), these 


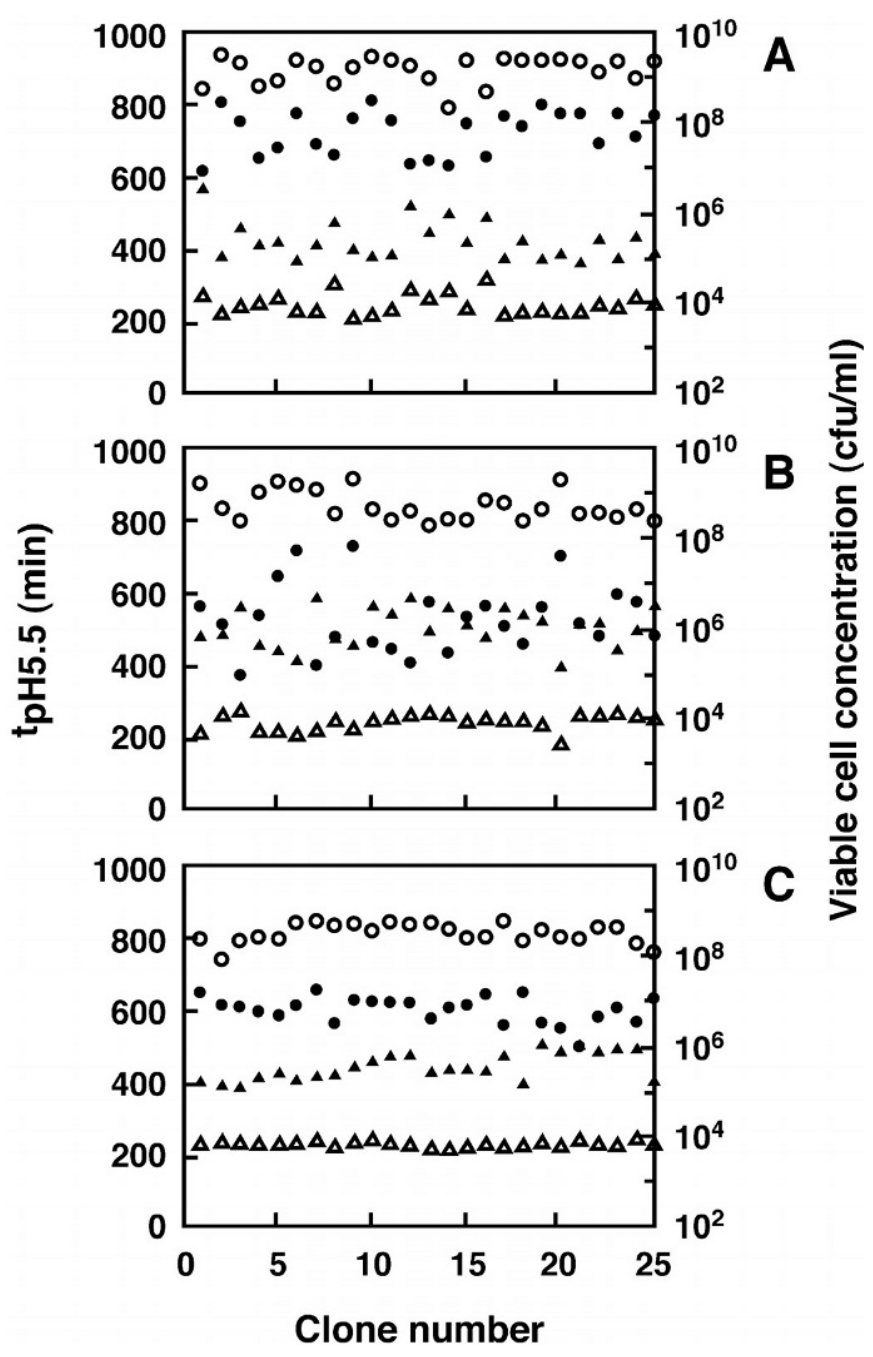

Figure 2. Viable cell concentration $(\bigcirc, \boldsymbol{\bullet})$ and time necessary to reach $\mathrm{pH} 5.5(\triangle, \mathbf{\Delta})$ before freezing (open symbols) and after thawing (closed symbols) in cultures of 25 clones isolated from cultures A (A), B (B), and C (C) after 30 cycles of subcultivation, freezing, and thawing.

results indicate that the evolution of the cultures cannot be explained by a possible contamination.

\section{Within-Population Diversity of the Cultures After 30 Cycles of Subcultivation, Freezing, and Thawing}

After the 30 cycles of subcultivation, freezing, and thawing, the cultures were inoculated onto MRS agar plates and 25 colonies were picked at random for each of the three parallel cultures. These clones were tested individually for their viability and acidifying activity during one cycle of subcultivation, freezing, and thawing. For the clones arising from culture A, there was significant diversity in the viable cell concentration before freezing (Figure 2A). The standard deviation of the logarithms of viable cell concentration was 0.30 units. This diversity cannot be explained by a low repeatability of the viable cell concentration measurements, as the standard deviation of repeated cultures of the same clone was always lower than 0.12 units. The diversity in the viable cell concentration after thawing was higher than that before freezing, as the corresponding standard deviation (calculated from the logarithm of the viable cell concentration) was 0.48 units. There was also diversity in the acidifying activity of the clones. Before freezing, the time necessary to reach $\mathrm{pH} 5.5$ varied from $197 \mathrm{~min}$ for clone 9 to $307 \mathrm{~min}$ for clone 16 , and after thawing, it varied from $352 \mathrm{~min}$ for clone 21 to $560 \mathrm{~min}$ for clone 1 . There was also a withinculture diversity in culture B (Figure 2B), as the standard deviations of the logarithm of viable cell concentration before freezing and after thawing were 0.34 and 0.76 units, respectively. The mean $t_{\mathrm{pH} 5.5}$ value after thawing in culture $\mathrm{B}$ was higher than in culture A (503 vs. $411 \mathrm{~min}$ ), whereas the mean viable cell concentration after thawing was lower $\left(8.7 \times 10^{6}\right.$ vs. $9.2 \times 10^{7}$ $\mathrm{cfu} / \mathrm{ml}$ ). Culture C (Figure 2C) showed a lower withinpopulation diversity than the two other cultures, as the standard deviation of the logarithm of viable cell concentration before freezing and after thawing was 0.22 and 0.30 units, respectively.

\section{DISCUSSION}

Lactic acid bacteria are often used in a concentrated frozen or freeze-dried form, but freezing causes a decrease in cell viability (to varying degrees). In the present study, we show that the cryotolerance of lactobacilli can be improved by performing successive cycles of subcultivation, freezing, and thawing. The survival rate of strain CFL1, which was $10^{-5}$, increased to $4.3 \times 10^{-2}$ after 30 cycles of subcultivation, freezing, and thawing. The acidifying activity of the cells after thawing also increased during the experiment, and it is likely that this evolution is the consequence of the higher concentration of viable cells after thawing. Indeed, there was a good relationship between the viable cell concentration in the thawed culture and the time needed for the subsequently inoculated culture to reach $\mathrm{pH}$ 5.5. One characteristic feature of the curves of the viable cell concentration and of the acidifying activity after thawing is that their evolution was not regular throughout the experiment. In the three parallel cultures, there were phases where a rapid evolution took place, whereas in other phases evolution was slow. This may be explained by the random appearance of new betteradapted spontaneous mutants that are able to outcompete the other genotypes. This phenomenon is called "periodic selection" (Dykhuizen, 1990). This may also 
explain why the evolution in the three parallel cultures was distinct, as there is no reason that these cultures contained the same better-adapted mutants and that these mutants had appeared at the same time. It is possible that the cultures would have continued to evolve if we had not stopped the experiment after 30 cycles of subcultivation, freezing, and thawing. Experiments with evolving populations of Escherichia coli have shown that fitness of the cells may increase even after 20,000 generations (Cooper and Lenski, 2000).

As L. delbrueckii ssp. bulgaricus CFL1 was very sensitive to the freezing conditions applied in the present study, there was high pressure for selection of spontaneous mutants that are more resistant to freezing. This also resulted in an increase of the acidifying activity of the thawed cultures. During the serial transfer culture experiment, cells were repeatedly exposed to low $\mathrm{pH}$ (all cultures reached a pH near of 3.7 to 3.9). Furthermore, after 30 cycles of subcultivation, freezing, and thawing, cultures were exposed to acidic conditions for a longer period than the initial cultures. Under these conditions, there may be a significant selection pressure for mutants that can survive better at low $\mathrm{pH}$. This could explain the increase of cryotolerance, as it is well known that mutations that improve resistance to a specific stress may also improve the resistance to other stresses (van de Guchte et al., 2002). However, as the cell counts after $24 \mathrm{~h}$ of growth were always near $5 \times$ $10^{8}$ to $10^{9} \mathrm{cfu} / \mathrm{ml}$, which is equivalent to the highest concentration of viable cells in culture of strain CFL1, there was no large decrease of viability during the exposure to low $\mathrm{pH}$. It thus seems reasonable to consider that the main cause of evolution of the cultures is rather the high lethality of strain CFL1 during the freezing and thawing treatments. To confirm this hypothesis, it would be interesting to perform a serial transfer culture experiment in which cells are not subjected to freezing and thawing treatments.

The acidifying activity before freezing also increased in the three cultures. In contrast to what was observed for the thawed cultures, this evolution could not be linked to a higher concentration of viable cells in the culture that is used for inoculating milk. Several hypotheses may explain this result. For example, the lag phase of the cells may have decreased after 30 cycles of subcultivation, freezing, and thawing. It is also possible that their growth rate had increased. An interesting issue is whether this evolution is the consequence of the selection of mutants having an improved cryotolerance or whether the two phenomena are independent. If the first hypothesis is true, it would mean that several mutations that improve the cryotolerance also improve the acidifying activity of cells. If not, it would mean that in these experiments, there is also a significant selection pressure for mutants harboring mutations that increase the acidifying activity and that have no effect on cryotolerance.

After 30 cycles of subcultivation, freezing, and thawing, the three cultures contained subpopulations with distinct cryotolerances and acidifying activities. This means that they were not composed of one single genotype that had previously outcompeted all the less adapted genotypes. One explanation for this withinpopulation diversity is that the genotypes that have the highest cryotolerance had not appeared for long enough to outcompete all the other genotypes. This implies that the cryotolerance of the three parallel cultures would still have increased if the experiment had been carried on after 30 cycles of subcultivation, freezing, and thawing. Another explanation for the presence of a significant within-population diversity in the cultures is that a polymorphism may persist, due to ecological interactions between genotypes, such as cooperation and competition. Rozen and Lenski (2000) observed that two distinct cell types of Escherichia coli coexisted for more than 14,000 generations in a serial transfer culture experiment.

It would be interesting to investigate the mutations that have improved the cryotolerance of $L$. delbrueckii ssp. bulgaricus CFL1 and to answer the following questions: 1) what are the genes that have been affected? 2) are these genes different from one population to another? and 3) are there important differences between the subpopulations? These results may help to define new targets for improving the resistance of lactic acid bacteria to several stresses.

In the present study, the acidifying activity of frozen cultures of $L$. delbrueckii ssp. bulgaricus CFL1 could be improved by applying high pressure for the selection of cells with an increased survival rate to freezing. However, it is likely that in the experiments that have been performed, there was only a limited selection pressure that concerns important technological properties such as the resistance of phages or the production of aroma compounds. These properties should thus be carefully checked if the use of such types of cultures is considered in industrial processes.

\section{CONCLUSIONS}

In the present study, we show that the cryotolerance of lactobacilli can be improved by performing successive cycles of subcultivation, freezing, and thawing. This approach may be used for improving the activity of concentrated frozen starter cultures. Furthermore, it is possible that other properties of lactic acid bacteria, such as the resistance to freeze-drying or spray-drying, may also be improved by natural selection. 


\section{ACKNOWLEDGMENTS}

We thank Béatrice Bonnet, Jérôme Delettre, Stéphanie Guilbert, and Almudena Bilbao for helpful technical assistance. We are grateful to Dominique Schneider and Christine Young for critically reading the manuscript.

\section{REFERENCES}

Akopyanz, N., N. O. Bukanov, T. U. Westblom, S. Kresovich, and D. E. Berg. 1992. DNA diversity among clinical isolates of Helicobacter pylori detected by PCR-based RAPD fingerprinting. Nucleic Acids Res. 20:5137-5142.

Béal, C., F. Fonseca, and G. Corrieu. 2001. Resistance to freezing and frozen storage of Streptococcus thermophilus is related to membrane fatty acid composition. J. Dairy Sci. 84:2347-2356.

Broadbent, J. R., and C. Lin. 1999. Effect of heat shock or cold shock treatment on the resistance of Lactococcus lactis to freezing and lyophilization. Cryobiology 39:88-102.

Cooper, V. S., and R. E. Lenski. 2000. The population genetics of ecological specialization in evolving Escherichia coli populations. Nature 407:736-739.

de los Reyes-Gavilan, C. G., G. K. Y. Limsowtin, P. Tailliez, L. Sechaud, and J. P. Accolas. 1992. A Lactobacillus helveticus-specific DNA probe detects restriction fragment length polymorphisms in this species. Appl. Environ. Microbiol. 58:3429-3432.

de Man, J. C., M. Rogosa, and M. E. Sharpe. 1960. A medium for cultivation of lactobacilli. J. Appl. Bacteriol. 23:130-135.

De Urraza, P., and G. De Antoni. 1997. Induced cryotolerance of Lactobacillus delbrueckii subsp. bulgaricus LBB by preincubation at suboptimal temperatures with fermentable sugar. Cryobiology 35:159-164.

Dykhuizen, D. E. 1990. Experimental studies of natural selection in bacteria. Annu. Rev. Ecol. Syst. 21:373-398.

Fonseca, F., C. Béal, and G. Corrieu. 2001. Operating conditions that affect the resistance of lactic acid bacteria to freezing and frozen storage. Cryobiology 43:189-198.

Hassan, A. N., and J. F. Frank. 2001. Starter cultures and their use. Pages 151-206 in Applied Dairy Microbiology. 2nd ed. E. H. Marth and J. L. Steele, eds. Marcel Dekker, Inc., New York, NY.

Kim, W. S., and N. W. Dunn. 1997. Identification of a cold shock gene in lactic acid bacteria and the effect of cold shock on cryotolerance. Curr. Microbiol. 35:59-63.

Lejard, F., P. Boyaval, H. De Roissart, and R. Maruejouls. 1994. Production de ferments concentrés pour ensemencement direct.
Pages 539-553 in Bactéries Lactiques. Aspects Fondamentaux et Technologiques. Volume 1. H. De Roissart and F. M. Luquet, eds. Lorica, Uriage, France.

Mazur, P. 1965. Causes of injury in frozen and thawed cells. Federation Proceedings. 24:S175-S182.

Meryman, H. T. 1968. Modified model for the mechanism of freezing injury in erythrocytes. Nature 218:333-336.

Panoff, J. M., S. Legrand, B. Thammavongs, and P. Boutibonnes. 1994. The cold shock response in Lactococcus lactis subsp. lactis. Curr. Microbiol. 4:213-216.

Panoff, J. M., B. Thammavongs, M. Gueguen, and P. Boutibonnes. 1998. Cold stress responses in mesophilic bacteria. Cryobiology 36:75-83.

Park, J. I., C. M. Grant, M. J. Davies, and I. W. Dawes. 1998. The cytoplasmic $\mathrm{Cu}, \mathrm{Zn}$ superoxide dismutase of Saccharomyces cerevisiae is required for resistance to freeze-thaw stress: Generation of free radicals during freezing and thawing. J. Biol. Chem. 273:22921-22928.

Poirier, I., P. A. Maréchal, and P. Gervais. 1998. Viability of lactic bacteria submitted to dehydration: importance of dehydration kinetics. Lait 78:173-180.

Rozen, D. E., and R. E. Lenski. 2000. Long-term experimental evolution in Escherichia coli. VIII. Dynamics of a balanced polymorphism. Am. Nat. 155:24-35.

Stead, D., and S. F. Park. 2000. Roles of Fe superoxide dismutase and catalase in resistance of Campylobacter coli to freeze-thaw stress. Appl. Environ. Microbiol. 66:3110-3112.

Teixeira, P., H. Castro, and R. Kirby. 1996. Evidence of membrane lipid oxidation of spray-dried Lactobacillus bulgaricus during storage. Lett. Appl. Microbiol. 22:34-38.

Teixeira, P., H. Castro, C. Mohacsi-Farkas, and R. Kirby. 1997. Identification of sites of injury in Lactobacillus bulgaricus during heat stress. J. Appl. Microbiol. 83:219-226.

Torriani, S., G. Zapparoli, and F. Dellaglio. 1999. Use of PCR-based methods for rapid differentiation of Lactobacillus delbrueckii subsp. bulgaricus and L. delbrueckii subsp. lactis. Appl. Environ. Microbiol. 65:4351-4356.

Tsvetkov, T., and I. Shishkova. 1982. Studies on the effects of low temperatures on lactic acid bacteria. Cryobiology 19:211-214.

van de Guchte, M., P. Serror, C. Chervaux, T. Smokvina, S. D. Ehrlich, and E. Maguin. 2002. Stress responses in lactic acid bacteria. Antonie van Leeuwenhoek 82:187-216.

Whitaker, R. D., and C. A. Batt. 1991. Characterization of the heat shock response in Lactococcus lactis subsp. lactis. Appl. Environ. Microbiol. 57:1408-1412.

Wouters, J. A., M. Mailhes, F. M. Rombouts, W. M. de Vos, O. P. Kuipers, and T. Abee. 2000. Physiological and regulatory effects of controlled overproduction of five cold shock proteins of Lactococcus lactis MG1363. Appl. Environ. Microbiol. 66:3756-3763. 